Article

\title{
Factors Affecting Farmers' Adaptation Strategies to Environmental Degradation and Climate Change Effects: A Farm Level Study in Bangladesh
}

\author{
Mohammed Nasir Uddin ${ }^{1}$, Wolfgang Bokelmann ${ }^{2}$ and Jason Scott Entsminger ${ }^{3, *}$ \\ 1 Department of Agricultural Extension Education, Bangladesh Agricultural University, \\ Mymensingh 2202, Bangladesh; E-Mail: nasirbau@gmail.com \\ 2 Division of Economic of Horticultural Production, Faculty of Agriculture and Horticulture, \\ Humboldt University of Berlin (HUB), Unter den Linden 6, 10099 Berlin, Germany; \\ E-Mail: w.bokelmann@agrar.hu-berlin.de \\ 3 Agricultural Business Management, Institute of Applied Agriculture, University of Maryland, \\ College Park, MD 20742, USA \\ * Author to whom correspondence should be addressed; E-Mail: jason.s.entsminger@gmail.com; \\ Tel.: +1-775-813-3740.
}

External Editor: Nicole Mölders

Received: 19 May 2014; in revised form: 22 August 2014 / Accepted: 26 August 2014 / Published: 26 September 2014

\begin{abstract}
Offering a case study of coastal Bangladesh, this study examines the adaptation of agriculturalists to degrading environmental conditions likely to be caused or exacerbated under global climate change. It examines four central components: (1) the rate of self-reported adoption of adaptive mechanisms (coping strategies) as a result of changes in climate; (2) ranking the potential coping strategies based on their perceived importance to agricultural enterprises; (3) identification the socio-economic factors associated with adoption of coping strategies, and (4) ranking potential constraints to adoption of coping strategies based on farmers' reporting on the degree to which they face these constraints. As a preliminary matter, this paper also reports on the perceptions of farmers in the study about their experiences with climatic change. The research area is comprised of three villages in the coastal region (Sathkhira district), a geographic region which climate change literature has highlighted as prone to accelerated degradation. One-hundred (100) farmers participated in the project's survey, from which the data was used to calculate weighted indexes for rankings and to perform logistic regression. The rankings, model results, and descriptive
\end{abstract}


statistics, are reported here. Results showed that a majority of the farmers self-identified as having engaged in adaptive behavior. Out of 14 adaptation strategies, irrigation ranked first among farm adaptive measures, while crop insurance has ranked as least utilized. The logit model explained that out of eight factors surveyed, age, education, family size, farm size, family income, and involvement in cooperatives were significantly related to self-reported adaptation. Despite different support and technological interventions being available, lack of available water, shortage of cultivable land, and unpredictable weather ranked highest as the respondent group's constraints to coping with environmental degradation and change effects. These results provide policy makers and development service providers with important insight, which can be used to better target interventions which build promote or facilitate the adoption of coping mechanisms with potential to build resiliency to changing climate and resulting environmental impacts.

Keywords: farmers' adaptation; climate change; Bangladesh

\section{Introduction}

The Intergovernmental Panel on Climate Change [1] forecasts that developing countries, like Bangladesh, will continue to be affected by extreme weather variability such as temperature, severe water shortage, and flood-inducing rainfall events during the coming decades. Weather variability and sea-level rise are the most pressing predicted consequences of climate change with a $0.6{ }^{\circ} \mathrm{C}$ global temperature change, $2 \%$ to $3 \%$ precipitation increase of the tropical latitudes and $3 \%$ precipitation decrease in subtropical areas within the 20th century. Scenarios predict global temperature could increase between $1.4{ }^{\circ} \mathrm{C}$ and $5.8{ }^{\circ} \mathrm{C}$ by the end of the 21 st century [2]. About 10 to 25 millimeters of sea-level rise was observed over the 20th century and models predict continued rise in a range of anywhere from 20 to 90 centimeters within the 21 st century [3]. Similarly, the most recent IPCC report has noted empirical models forecasting a lengthening and intensification of precipitation periods, notably the Indian/South Asian subsystem of the Asian-Australian Monsoon. The inundation of land areas through sea-level rise and increased precipitation is not the only worrisome effect of global climate change; the literature reviewed and reported by the IPCC also notes drought events as well. In the final decades of the 20th century roughly 2.7 million ha of land in Bangladesh alone were vulnerable to annual drought with a $10 \%$ probability that $41 \%-50 \%$ of the country experiencing drought in a given year and those figures are forecast to increase in both geographic scope and event intensity [3,4]. Critically for this study, the Indian/South Asian summer monsoon subsystem "is known to have undergone abrupt shifts, giving rise to prolonged and intense droughts". The investigations reported in the 2013 IPCC report come to central conclusion about the South Asian region under global climate change models: "normal" monsoon seasons are seen as less likely, leaving uncertainty about the extremes to be experienced in the region [3].

The prediction of climatic changes have the potential to severely affect countries highly dependent upon agrarian livelihoods, resulting in food shortages, among other consequences. Therefore, people who depend on farming activities will require a variety of adaptation strategies to mitigate the negative 
effects of climate change effects and maintain the livelihoods of farming families. Different modern technologies have been developed and introduced at the farm level in order to achieve target measures of the Millennium Development Goals [5]. Specific adaptation strategies to climate change effects include changing the timing of planting and using heat and drought resistant varieties [6-9] with new cultivars having been selected and applied for the same purposes [10,11]. Practicing soil and water conservation techniques [12], fertilizer use, irrigation [9,13] and diversification to non-farm activities [7,14] are also adaptation strategies that have been practiced at farm level in response to climate change.

Bangladesh is considered to be one of the countries most vulnerable to climate change and its effects on environmental degradation because of its geographic location. These impacts on average temperature and precipitation have a baseline impact on the productive capacity of agricultural activity, altering the underlying yield expectations and risk regimes faced by farmers [15]. Additionally, the region faces recurrent, climate-related natural disasters; about 174 events such as floods, droughts, and cyclones, have affected Bangladesh from 1974 to 2007. These natural disasters have damaged agriculture and its production in ways that severely affected the farming activities and national economy as well $[16,17]$. By way of example, cyclones hit Bangladesh, on average, every three years, causing serious damage to the people, infrastructure, and agriculture of the country. In 1970 and 1991, cyclones killed 500,000 and 140,000 people, respectively [18,19]. An estimate made by the Government of Bangladesh (GoB) about the destruction and loss in the country due to the Cyclone Sidr [16] found significant damage to infrastructures, assets, and loss of production; specifically within the agricultural sector these losses were valued at US \$438 million, which accounts for approximately $95 \%$ of the total losses to all sectors. Table 1 indicates the sector-wide values (in millions of US Dollars) of damage and economic losses in agriculture. The frequency and magnitude of such climate-related natural disaster events are likely to be affected by global climate change, compounding the baseline effects on agricultural production which can be expected under global climate change models.

Table 1. Estimated damage and losses of agriculture during Cyclone Sidr in Bangladesh.

Sources: Government of Bangladesh (GoB), 2008 [16].

\begin{tabular}{cccc}
\hline \multirow{2}{*}{ Name of the Sub-Sectors } & \multicolumn{3}{c}{ Disaster Effects ( Million US\$) } \\
\cline { 2 - 4 } & Damage & Loss & Total \\
\hline Crop & - & 411.60 & 411.60 \\
Livestock & 19.30 & - & 19.30 \\
Fisheries & 2.00 & 4.70 & 6.70 \\
Total & 21.30 & 416.30 & 437.60 \\
\hline
\end{tabular}

Frequent natural hazards due to climate change affect agricultural enterprises and, subsequently, the key to agricultural production activities- farm households- are also severely affected. Some farm households have already altered their production strategies in response to environmental degradation (regardless of cause) and weather variability associated with climate change effects. Such changes in production strategies are referred to in this paper as coping strategies. Choices about management practices, enterprise types, and genetic varieties of crops, have been adapted by farmers according to soil properties, location, and climatic conditions. Proper management systems such as weeding, 
mulching, irrigation with fresh water, and thinning applied by the farmers can help overcome salinity and drought. Recently, a number of varietals adapted for salinity and drought tolerance have been used for planting, but it is not widespread throughout the country [17]. Farmers' responses to climate change effects, as well as use of adaptation strategies, are influenced by their socio-economic characteristics, with knowledge of the farmers being the most influential [20].

There is a growing consensus that neither sound technological protocols, nor local techniques, suffice per se to enhance farmers' capacity to overcome climate related risks and challenges. The integration of sound technological solutions with local practices is increasingly identified as a more-necessary pathway. In Bangladesh, research and development programs are tailored to provide technological solutions to farmers through cooperative extension systems and other means, leading farmers in Bangladesh to implement various coping strategies [21,22], strategies which have been identified within the prevailing literature as potential avenues for mitigating climate change effects. However, the empirical research regarding these adaption strategies has not documented how farmers adapt their farming practices in relation to the continuous and sudden changes in climatic events, nor identified what are the important socio-economic factors which contribute (or hinder) their adaptation. While largely absent, what little evidence does exist is mostly anecdotal. Therefore, there is an urgent necessity to identify the strategies that are best suited to support farmers and farming communities in this period of climate change and to identify the factors affecting the farmers' adoption of adaptive strategies to climate change. Farmers in Bangladesh at present face increasing environmental degradation which is the result of multiple source-points; this degradation is both similarly situated to and likely to be exacerbated under the increasing effects of global climate change. This paper focuses on identifying socio-economic factors likely to be influential in adaptive behavior, along with the perception of farmers about challenges faced in adopting coping strategies. It is important to note that empirical analysis of climatic events and their causation lies well beyond the scope of our research and that this paper represents a jumping-off point for further studies which can later elucidate causation of adaptive strategy adoption.

\section{Methodology}

Three villages of the coastal region (Sathkhira district) in Bangladesh were considered as the study area. This region is one of the most affected areas compared to other parts of the country due to frequent climatic hazards such as floods, cyclones, tidal forces and increased salinity even drought in dry seasons [17]. Moreover, Cyclone Sidr (2007) and Cyclone Aila (2009) were severely affects the coastal part of this country and damage huge resources especially the farm resources. Consequently, farming of this area is highly affected; moreover, farming specially crop farming decreasing because of its transfer into the fish farming especially shrimp farming. Therefore, both natural and anthropogenic issues affects the farming activities in this area. About 100 farmers were interviewed using a structured questionnaire administered in May 2012. Respondents were selected using a randomized lottery, with lots draw from a listing of farmers within the region compiled by local extension service agents. STATA (a statistical software package) was used to analyze the collected data including descriptive statistics- such as mean, number, standard deviation, range, and percentage- and econometric analysis. 
Elements of the survey questionnaire collected information on major components: (1) self-reported adoption of pre-determined climate change mitigation strategies by the farmer; (2) rating of the importance of the array of adaptive strategies to the farmer's practices; (3) the degree to which specific problems that might hinder adoption of coping strategies had been encountered; and (4) demographic information of the household focused on key socio-economic factors. Response options for components (2) and (3) were placed on a continuum (Likert scale) as high, medium, low and not at all. Scores assigned to responses were $3,2,1$, and 0 , respectively.

Adaptation is a dependent dummy-variable in the data. The dummy was determined by assigning a value of 1 for farmers who indicated that they had taken adaptive measures in response to negative effects of climate change and a value of 0 for farmers who indicated they did not engage in any adaptive measures at all in response to negative effects of climate change. For instance, if a farmer uses at least one coping strategy to abate the negative consequences of climate change then that famer is considered to have "adapted" (1). During the enumeration of the survey, respondents were presented with an scripted explanation of practices and behaviors vis-à-vis climate change adaptation strategies, then presented with a simple dichotomous ("yes/no" response) question about whether or not they had adopted any of these behaviors due to changing climate in the region, making results here self-reported.

Different strategies are practiced by various farmers, which enhance the farmer's adaptation to climate change (see Section 3.3). However, adaptation strategies to climate change effects also depend on the socioeconomic characteristics of the farmers. For instance literate farmers may take different adaptive measures compared to those who are illiterate. Moreover, annual family income, farm size, farming experiences, and contact with extension service agents influence the famers' use of adaptive measures to adjust to environmental degradation and severe weather events resultant from climate change effects. Regardless of the strategies applied by any farmer, it is predicted that taking adaptive measures reduces the negative effects of climate change on farm production, household income and farmer livelihoods.

In determining the econometric form to employ for this analysis, three options traditionally utilized to evaluate qualitative dependent variables, such as the dichotomous outcome of "Adapted" and "Not Adapted", were considered: Linear Probability Models (LPM), probit models, and logit models. Use of LPM is unnecessarily simple in its functional form, and presents the drawbacks of (1) a disturbance term which has a non-normal distribution leading to problems with making valid statistical inferences, (2) assumed heteroskedasticity of the error term which violates the principles of OLS and resulting estimators inefficient, (3) significant lack of meaningful models due to a lack of Goodness of Fit, and (4) without restrictions placed on beta-coefficients, LPM results can imply probabilities beyond the realm of the Bernouli distribution (that is that results lie beyond and between 0 and 1) due to the underlying assumption of linearity, and thus constancy [23,24]. Thus, LPMs are essentially ruled out for appropriate application in the case of this research, if more appropriate techniques are available.

Probit and logit models are extraordinarily similar in both their formulation and their results, relying on a "link" function using cumulative distribution functions (CDFs) which are normally and logistically distributed, respectively. As is well-known, these CDFs present a sigmoid (S-shaped) distribution, which more closely resembles the observed distribution of dichotomous data [24]. These models do not use Ordinary Least Squares methodology, but instead rely upon Maximum 
Likelihood Estimation. The features of probit and logit models make interpretation of resulting coefficients unique from those obtained under an LPM. Of the two, probit models are often seen as better suited for experimental data [25] and do not enable precision robustness as they fail to allow the modeler to adjust for covariates. Logit models guarantee the estimated probability increases and never cross the range of 0 to 1 , and are the most commonly and widely applied. Therefore, Linear Probability Model (LPM) and probit models were rejected in favor of a logit model formulation. This logit model was used to identify the socio-economic factors affecting the farmers' adoption of adaptive strategies, using the functional form of logit model expressed by Gujrati [20] as:

$$
\mathrm{P}_{\mathrm{i}}=1 / 1+\mathrm{e}^{-\left(\beta_{\mathrm{o}}+\beta \mathrm{ixi}\right)}
$$

For simplicity equation 1 can be expressed as

$$
P_{i}=1 / 1+e^{-z i}
$$

where,

$\mathrm{P}_{\mathrm{i}}$ : Probability of adaptation of the $\mathrm{i}^{\text {th }}$ respondent

$\mathrm{e}^{\mathrm{zi}}$ : stands for the irrational number $e$ raised to the power of $\mathrm{Zi}$

$\mathrm{Zi}$ : is a function of $\mathrm{N}$-explanatory variables and expressed as:

$$
\mathrm{Zi}=\beta_{0}+\beta_{1} \mathrm{x}_{1}+\beta_{2} \mathrm{x}_{2}+\ldots+\beta_{n} \mathrm{x}_{n}+\mu_{\mathrm{i}}
$$

where,

$\beta_{0}=$ Constant term

$\beta_{1}, \ldots, \beta_{n}=$ Regression co-efficient

Therefore,

$$
\begin{gathered}
\mathrm{Zi}=\beta_{0}+\beta_{1}(\mathrm{AGE})+\beta_{2}\left((\mathrm{EDU})+\beta_{3}(\mathrm{FMLYSZ})\right)+\beta_{4}(\mathrm{FARMSZ})+\beta_{5}(\mathrm{FMLYIN}) \\
\left.+\beta_{6}(\mathrm{CRRE})+\beta_{7}(\mathrm{TRRE})+\beta_{8}(\mathrm{COIN})+\beta_{9}(\mathrm{MARAC})\right)+\mu
\end{gathered}
$$

Prior to the estimation of the logit model, the explanatory variables were checked for the existence of multi-colinearity, using a contingency coefficient test. Based on results of this procedure variables farming experience, number of plots, and contact with extension service agents are omitted from the final model.

\section{Findings and Discussion}

\subsection{Farmers' Perceptions on Experiencing Climate Change}

All of the respondents were asked a dichotomous ("yes/no" response) question about whether or not they had experienced changes to regional climate within the past 20 years. After their initial response, they were asked about their perceived experience in relation to a series of climatic events commonly associated within the literature reviewed for this study with global climate change effects in Bangladesh. To these they could respond that they had experienced decreases, increases, or no change in the occurrence of the event, or to respond that they did not know. Figure 1 reports the responses to the first question; some $88 \%$ of respondents indicated that, within the last 20 years, they have, in their view, experienced climatic change. Table 2 reports their responses for individual climatic events. Here, all respondents indicated that they had experienced increases in temperature, droughts, flooding, cyclones, 
and soil salinity. Across all events, at least $80 \%$ or more reported having experienced climatic shifts which are likely to have a negative impact on agricultural activity. While it is clear that these are perceptions of farmers, such information provides an important background of the respondent group.

Figure 1. Proportion of respondents by self-reported experience of climatic change.

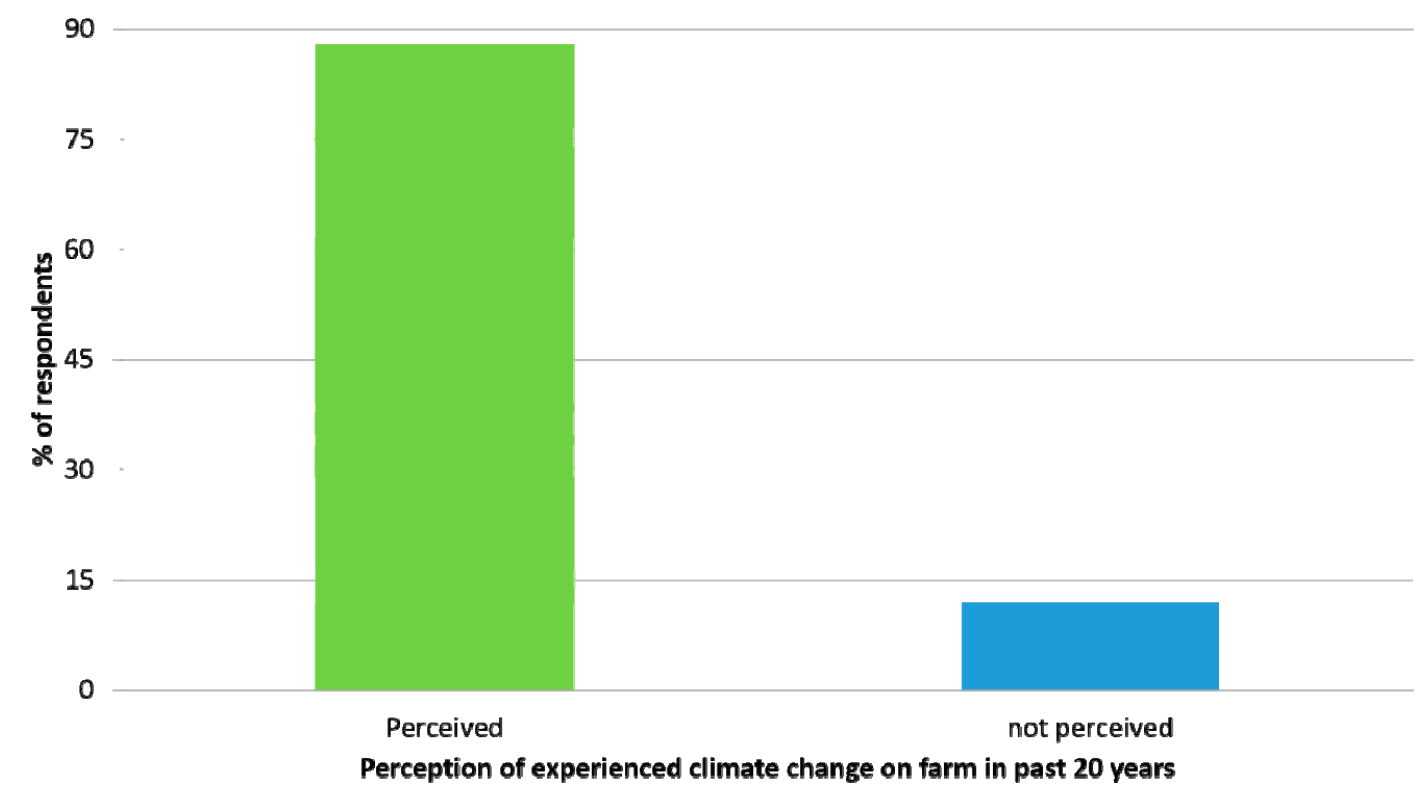

Table 2. Distribution of responses to perceived changes in specific climatic events $(n=88)$.

\begin{tabular}{|c|c|c|c|c|}
\hline \multirow[t]{2}{*}{ Climatic Event } & \multicolumn{4}{|c|}{$\begin{array}{l}\% \text { of Respondents Indicating to What Level they Have Experienced the Climatic } \\
\text { Event over the Last } 20 \text { Years }\end{array}$} \\
\hline & Increased & No Change & Decreased & Don't Know \\
\hline Temperature & 100 & & & \\
\hline Rainfall & & 3.4 & 96.6 & \\
\hline Occurrence of drought & 100 & & & \\
\hline Occurrence of flood & 100 & & & \\
\hline $\begin{array}{l}\text { Occurrence of } \\
\text { cyclones }\end{array}$ & 100 & & & \\
\hline Salinity level & 100 & & & \\
\hline Short winter season & 85.2 & 4.6 & & 10.2 \\
\hline Long summer season & 92 & 2.3 & & 5.7 \\
\hline Unpredictable rainfall & 90.9 & 1.1 & & 8 \\
\hline $\begin{array}{l}\text { Changes of monsoon } \\
\text { season }\end{array}$ & 80.7 & 2.3 & & 17 \\
\hline
\end{tabular}

\subsection{Farmers' Adaptation Strategies to Climate Change}

An overwhelming majority (84\%) of respondent farmers indicated that they had employed at least one of the identified adaptive strategies, with only $16 \%$ indicating no adoption of any of the adaptive strategies included in this study (see Figure 2). This stands as evidence supporting a conclusion that farmers of this area were taking actionable steps and changing practices to tackle various, known and 
unforeseen climatic and environmental changes. Dhaka et al. also found in their study that the majority of the farmers were using various adaptation strategies in response to climate change [26].

\subsection{Adaptation Strategy Index}

To identify those adaptive strategies which held relative importance over others an adaptation index procedure was implemented, as measured by the formula presented below (5). Farmers were asked to assess different adaptation strategies by using the same four-point rating scale described in Section 2 to rate the importance of each strategy to their agricultural enterprises. The relative importance of adaptation strategies to climate change was calculated based on the following index formula [17]:

$$
\mathrm{ASI}=\mathrm{AS}_{n} \times 0+\mathrm{AS}_{1} \times 1+\mathrm{AS}_{m} \times 2+\mathrm{AS}_{h} \times 3
$$

where,

ASI $=$ Adaptation Strategy Index

$\mathrm{AS}_{n}=$ Frequency of farmers rating adaptation strategy as having no importance

$\mathrm{AS}_{1}=$ Frequency of farmers rating adaptation strategy as having low importance

$\mathrm{AS}_{m}=$ Frequency of farmers rating adaptation strategy as having moderate importance

$\mathrm{AS}_{h}=$ Frequency of farmers rating adaptation strategy as having high importance

Figure 2. Proportion of respondents by adaptation classification.

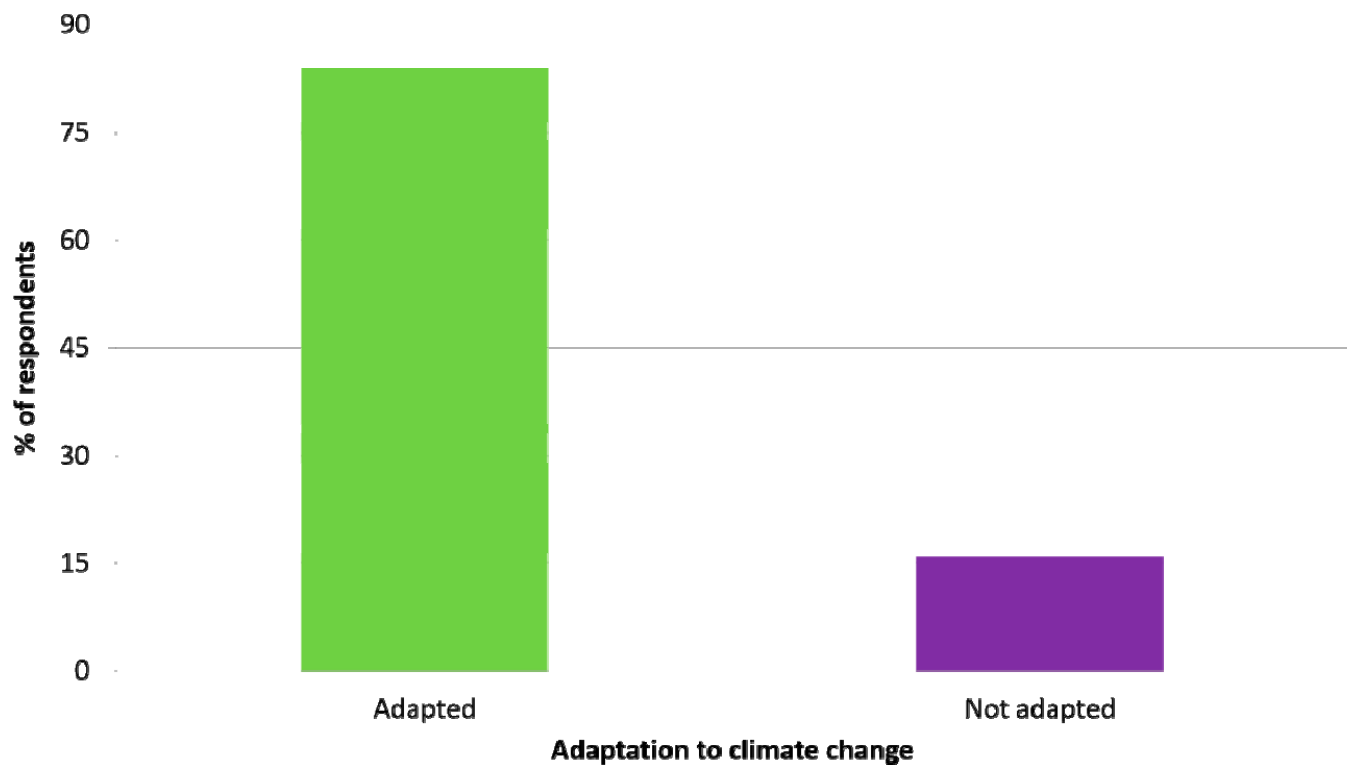

The salinity problem and droughts are the most common disasters in the region (south-western Bangladesh) where the study was conducted [27-29]. These two climatic disasters tremendously affect the crop production system. The ranking of different adaptation strategies to climate change, as identified by the surveyed farmers, are presented in Table 3. Out of 14 adaptation strategies, increased use of irrigation was ranked first and thus most important, among farmers' adaptive strategies to climate change. Irrigation increases the yield of production [30,31], improving nutrient availability to the plants but also leading to increased soil salinity [32,33]. Practicing crop diversification was identified as the second-ranked adaption strategy. Continuous mono-cropping (for example rice cultivation) has 
different adverse effects which include pest resurgence, and soil quality deterioration, in addition to the issues of loss risk associated with monocultures. In response to these effects, farmers adopt diversified cropping practices, reducing overall farm risk and expanding opportunities for farm profit, which generally act to boost the farmers' average incomes. The third most important adaptation strategy was the "integrated farming system" (being engaged in two or more enterprises which act symbiotically with one-another). This farming system is becoming more popular throughout the country because of its economic returns [34-37]. Crop insurance was ranked as the least important adaptation strategy. This is most likely due to (1) a significant lack of good management of finance institutions in the country underwriting agriculture and offering farm-based insurance products, (2) poor deployment of technical assistance and low-levels of farmer awareness about the use of agricultural insurance, (3) only a very recent abatement of governmental regulations and policies which placed prohibitive restrictions on insurance provision entities, and (4) an overall lack of capacity (financial, infrastructure, and human) among in-country financial institutions to float insurance programs [38].

Table 3. Ranked order of the adaptation strategies to climate change $(n=84)$.

\begin{tabular}{ccccccc}
\hline \multirow{2}{*}{ Adaptation Strategies } & \multicolumn{3}{c}{ Importance of Your Farm } & \multirow{2}{*}{ ASI } & \multirow{2}{*}{ Rank } \\
\cline { 2 - 6 } & High & Medium & Low & No & & \\
\hline Increased use of irrigation & 75 & 9 & - & - & 243 & 1 \\
Practicing crop diversification & 51 & 32 & 1 & - & 218 & 2 \\
Integrated farming system & 47 & 36 & 1 & - & 214 & 3 \\
Use of drought tolerant varieties & 47 & 35 & 1 & 1 & 212 & 4 \\
Use of salinity tolerant varieties & 48 & 29 & 2 & 5 & 204 & 5 \\
Practicing crop rotation & 38 & 40 & 4 & 2 & 198 & 6 \\
Cultivating short duration crops & 31 & 50 & 3 & - & 196 & 7 \\
Practicing intercropping & 13 & 50 & 20 & 1 & 159 & 8 \\
Find off-farm job & 20 & 35 & 27 & 2 & 157 & 9 \\
Moved to Non-farm activities & 11 & 49 & 22 & 2 & 153 & 10 \\
Agro forestry & 1 & 25 & 47 & 11 & 100 & 11 \\
Soil conservations techniques & 2 & 20 & 52 & 10 & 98 & 12 \\
Zero tillage & 5 & 21 & 48 & 10 & 63 & 13 \\
Crop insurance & - & 5 & 12 & 67 & 22 & 14 \\
\hline
\end{tabular}

\subsection{Econometric Estimation of Factors Affecting the Farmers' Adaptation Strategies to Climate}

\section{Change Effects}

Before the data analysis, the contingency coefficient test was applied to diagnose colinearity and omit independent variables that are highly dependent and strongly correlated to each other (Table 4).

Multi-colinearity was observed between farming experience and age, extension contact and education, number of plots and farm size, family income and farm size, family income and number of plots, extension contact and cooperative involvement. Generally, it is predicted that there should be a positive relationship between family income and farm size, very important variables that might also affect the decision to adopt adaptive strategies to climate change. Therefore, both were considered in the logit model reported here instead of excluding them from the analysis. The model was run with these items omitted and the econometric estimates in those simulations were found to not have significantly 
changed from the model which maintains these two variables reported here. Only farming experiences, extension contact, and the number of plots are omitted from the logistic regression model in determining factors affecting the farmers' adaptation strategies to climate change effects, as shown in Table 5.

Table 4. Contingency coefficient test for co-linearity between independent variables.

\begin{tabular}{|c|c|c|c|c|c|c|c|c|c|c|c|}
\hline Variables & AG & EDU & FAMSZ & FARSZ & NUMP & FAREX & FAMIN & CRRE & TRRE & COPIN & MARAC \\
\hline $\mathrm{AG}$ & 1 & & & & & & & & & & \\
\hline EDU & -0.046 & 1 & & & & & & & & & \\
\hline FAMSZ & 0.368 & 0.114 & 1 & & & & & & & & \\
\hline FARSZ & 0.213 & $0.393 *$ & $0.354 *$ & 1 & & & & & & & \\
\hline NUMP & 0.181 & $0.35 *$ & $0.382 *$ & $0.853 * *$ & 1 & & & & & & \\
\hline FAREX & $0.887 * *$ & -0.114 & $0.360 *$ & 0.163 & 0.162 & 1 & & & & & \\
\hline FAMIN & 0.195 & $0.344 *$ & 0.229 & $0.893 * *$ & $0.639 * *$ & 0.131 & 1 & & & & \\
\hline CRRE & 0.223 & 0.113 & 0.117 & 0.202 & 0.254 & 0.178 & 0.139 & 1 & & & \\
\hline TRRE & 0.095 & 0.331 & 0.143 & $0.344 *$ & $0.341 *$ & 0.009 & 0.245 & $0.363 *$ & 1 & & \\
\hline COPIN & 0.048 & $0.506 *$ & 0.158 & $0.347 *$ & $0.36^{*}$ & -0.040 & 0.237 & 0.242 & $0.343 *$ & 1 & \\
\hline MARAC & 0.054 & $0.495 *$ & 0.171 & 0.236 & 0.288 & 0.034 & 0.166 & 0.270 & 0.188 & $0.410 *$ & 1 \\
\hline EXCONT & 0.032 & $0.756 * *$ & 0.164 & $0.457 *$ & $0.446 *$ & 0.018 & $0.391 *$ & 0.155 & $0.355 *$ & $0.526 * *$ & $0.398 *$ \\
\hline
\end{tabular}

* Weak co-linearity between the two variables ** High co-linearity between the two variables.

Table 5. Estimates of binary logit regression model based on farmers' adaptation strategies to climate change effects.

\begin{tabular}{cccc}
\hline \multirow{2}{*}{ Variables } & \multicolumn{3}{c}{ Adaptation } \\
\cline { 2 - 4 } & Coefficient & Robust Std. Error & $\boldsymbol{p}$ Value \\
\hline CONS & 0.905 & 3.12000 & 0.772 \\
AGE & $-0.110^{*}$ & 0.06550 & 0.092 \\
EDU & $1.215 * *$ & 0.59820 & 0.042 \\
FAMSZ & $-2.174 * *$ & 0.77470 & 0.005 \\
FARSZ & $-10.105 * *$ & 3.3480 & 0.003 \\
FAMIN & $0.0002 * *$ & 0.00008 & 0.002 \\
CRRE & -1.685 & 2.31900 & 0.467 \\
TRRE & 7.231 & 4.50200 & 0.108 \\
COIN & $7.029 *$ & 3.76700 & 0.062 \\
MARACC & 0.003 & 1.49100 & 0.998 \\
Pseudo R ${ }^{2}$ & & 0.875 & \\
\hline
\end{tabular}

$* *, *$ indicate significant level at $5 \%$ and $10 \%$ respectively.

The findings of the regression model (Table 5) indicate that age is negative and significantly (at $10 \%$ level) related to farmers' adaptive strategies to climate change effects. This implies that the probability of adaptation significantly decreases the older a respondent farmer. It can be predicted that such farmers have less interest or less incentives in taking climate change adaptation measures. Perhaps older farmers do not see the necessity to adapt to climate change effects. Moreover, these older farmers may be more "set in their ways", interested in following traditional methods familiar to them rather than adopting modern farming techniques. The similar outcome have found and explained in the articles written by Acquah and Quayum et al. $[39,40]$. 
The regression model results explain that education is positive and significantly (at $5 \%$ level) related to adaptation strategies to climate change effects. This implies that the probability of adaptation to climate change is greater for those who have higher educational attainment compared to less-educated or illiterate farmers. It is obvious that educated farmers have more knowledge, a greater ability to understand and respond to anticipated changes, are better able to forecast future scenarios and, overall, have greater access to information and opportunities than others, which might encourage adaptation to climate change. Several studies found that education also positively and significantly affects the adoption of technology [40-45].

Family size is negative and significantly (at 5\% level) related to farmers' adaptation strategies to climate change effects. However, the negative sign on this relationship is contradictory to our initial hypothesis. This negative sign indicates that with increasing size of the family, the probability of farmers' adoption of an adaptive strategy decreases. Prior to this study it was expected that the sign of the variable family size would have a positive sign, the logic being that large family size makes available more labor which can actively engage in work, better facilitating the adoption of adaptive measures against climate change effects, ceteris paribus. This assumption was in line with the results of similar work on climate change adaptation strategies done by Deressa et al. (2008, 2009), as well as the large body of literature on technology adoption such as Mignouna et al.(2011), Tiamiyu et al. (2009) and many others [20,46-48].

Given our negative results, we turned towards a deeper look at the literature on labor availability within the household and its impact on propensity to adopt new technologies or farming strategies. From this review we theorize a variety of potential explanations for the negative sign found in our work: (1) if there are sufficient opportunities for off-farm labor, which would increase household liquidity at a greater rate than on-farm activities, then there will be a flight to quality of a household's labor endowments and a reduction in actual internal labor availability; (2) if subsistence farming is predominant among the households in the sample, then the same labor shortages assumed to be hindering adoption in income-generating agricultural activity may not be present; (3) there may be a timing issue with the increased labor demands needed to implement adaptive strategies; (4) labor markets are seen to be intertwined with credit markets, and thus if there is insufficient access to credit which can offset the lag in income between switching labor from off-farm income generation to on-farm adaptive strategies, then a larger household will choose not to reallocate labor and adopt new, more labor-intensive strategies; (5) it may be that households with an abundance of labor face risk premiums and opportunity costs different than those with less labor endowments, thus leading them to supplement labor to cope with climate change as the less expensive allocation decision compared to other investments that would be required to adopt coping strategies; or (6) a majority of the additional family members are children and/or the elderly, therefore we may assume an overestimate of labor availability using household size, and, in fact, the distribution of household members and their endowments may be a contributing factor to the risk acceptance-aversion factor of a farm household, leading them to view adaptive strategy adoption as "too risky" given their circumstances [49-53]. These areas provide rife opportunity for further empirical study to provide evidence as to which, if any, is connected with the observation of a negative sign of the coefficient and its statistical significance. Other studies, such as that of Quayum and Ali (2012) [40] have shown that 
family size was negatively and significantly related to adoption of technologies, but there is no definitive causation shown in the literature reviewed for preparing this work.

There is a negative and significant (at 5\% level) relationship between farm size and adaptation to climate change effects. Specifically, results show that increasing size of a farm operation decreases the probability of farmers' adoption of adaptive strategies to climate change. The reason behind this result may be the large farmers were deployed traditional technologies rather modern technologies to climate change adaptation. Moreover, large farms require greater levels of investment to implement adaptive strategies to climate change, therefore, farmers of the study failed to do that compared to small farm. Acquah explained the similar result while farm size showed negatively significant with adaptation to climate change effects [39]. Moreover, larger farms require inputs such as seeds, fertilizer, pesticides, irrigation facilities, and more at rates which are stressors on farm budgets. For adaptation behaviors it may be that these inputs were not available or are too expensive in the study area at sufficiently large quantities. Another potential explanation, may be that all inputs were available but, due to a lack of proper management capacity in relation to farm size, large farms fail to adapt efficiently. Scarcity of labor may also be and additional motive not to engage in adaptive strategy adoption.

The result of the logistic regression shows that positive and significant (at $5 \%$ level) relationship between family income and adoption of adaptive strategies to climate change effects. This implies that farmers with high income are more likely to adopt adaptive strategies than farmers with lower incomes. The findings support projects undertaken by Government Organizations (GOs) and Non-Government Organizations (NGOs) designed to create off-farm livelihoods activities so that farmers can diversify and supplement their income and continue their agricultural operations in the face of climatic uncertainty. On the other hand, remittances and off-farm jobs might also be another source of annual family income of the farmers. Kim et al. found that household income positively and significantly influences the adoption of adaptive to climate change [54] while Gbeibouo (2009) explained that wealthier farmers are more interested to adapt by changing planting practices, using irrigation, and altering the amount of land farmed [55]. Further, Nhemachena and Hassan indicate that per capita income has a positive influence on farmers' decisions to take-up adaptation measures [56].

Involvement in cooperatives is positive and significantly (at 10\% level) related to adoption of adaptation strategies, implying that the probability of adaptive strategy adoption in higher for those farmers who have connections with different cooperatives enterprises compared to farmers not participating in such coordinated actions and groups. We interpret this observation as an indication that membership and engagement in a cooperative encourages farmers to engage in a united strategies orientation; farmers involved in cooperatives share knowledge and innovation ideas, discuss problems and challenges with others, and engage in collaborative decision-making.

Credit received, training received, and market access coefficients were not statistically significant in the model. In certain ways these results are surprising in light of the rhetoric and theory surrounding their use as development instruments in the general case and as climate change adaptation strategies in general. While there is much that could be said about the sign of the coefficients reported here, we forego such discussion given the statistical insignificance of the terms in the calculated model. Further research with larger data sets may present different results than those here, but the lack of significance in this model creates a clarion call for attention to the influence these stalwarts of rural development policy play in terms of promoting adaptive strategy adoption by farmers. 


\subsection{Constraints to Adopting Coping Strategies Faced by Farmers}

Table 6 summarizes the problems identified by farmers which can hinder or constrain adoption of the climate change coping strategies identified and investigated in this report and this sections discusses the related results. Similar to previous sections, a ranking of the problems was completed using a Problem Confrontation Index (PCI) value as estimated by using the formula (6) below [57,58]. Survey respondents were asked to rate their perception of each constraint on a four-point Likert scale ranging from "not encountered" to "high".

$$
\mathrm{PCI}=\mathrm{P}_{n} \times 0+\mathrm{P}_{1} \times 1+\mathrm{P}_{m} \times 2+\mathrm{P}_{h} \times 3
$$

where,

PCI $=$ Problem Confrontation Index

$\mathrm{P}_{n}=$ Frequency of the farmers who rated the problem as not encountered

$\mathrm{P}_{1}=$ Frequency of the farmers who rated the problem as low

$\mathrm{P}_{m}=$ Frequency of the farmers who rate the problem as moderate

$\mathrm{P}_{h}=$ Frequency of the farmers who rated the problem as high

Based on the results of the formula, the problems were listed in rank-order, also presented in Table 6. The results indicate that "lack of available water (both irrigation and drinking)" ranked first and seems to be the most severe problem of the farmers in the region studied in terms of adoption of climate change adaptation strategies. Agricultural production systems have been highly reliant on water, especially for irrigation, while rivers, rainfall, groundwater, canal water, etc., have been used as a source of this irrigation water. Available water is hard to manage-either for crop production or drinking water- in the coastal region of Bangladesh due to frequent natural disasters such as floods, droughts, and cyclones. Different GOs, NGOs and even farmers have been working on the water issues.

Table 6. Rank of the problems faced by the farmers.

\begin{tabular}{cccccccc}
\hline \multirow{2}{*}{ Problems } & \multicolumn{5}{c}{ Degree of Problems } & \multirow{2}{*}{ PCI } & \multirow{2}{*}{ Rank } \\
\cline { 2 - 5 } & High & Medium & Low & Not at All & & \\
\hline Lack of available water & 99 & 1 & 0 & 0 & 299 & 1 \\
(both irrigation and drinking) & & & & & & \\
Shortage of land & 88 & 12 & 0 & 0 & 288 & 2 \\
Unpredicted weather & 77 & 20 & 3 & 0 & 274 & 3 \\
Lack of credit/money & 55 & 44 & 1 & 0 & 253 & 4 \\
Lack of market access & 22 & 56 & 22 & 0 & 200 & 5 \\
Lack of farm animals & 13 & 56 & 30 & 1 & 181 & 6 \\
Shortage of farm inputs & 11 & 55 & 34 & 0 & 177 & 7 \\
Lack of information & 18 & 39 & 41 & 2 & 173 & 8 \\
Poor soil fertility & 5 & 23 & 71 & 1 & 132 & 9 \\
Insecure property rights & 1 & 29 & 62 & 8 & 123 & 10 \\
\hline
\end{tabular}

"Shortage of cultivable land" was ranked as the second most severe problem. With the growing population, cultivable land is increasingly being utilized for non-farm sectors such as housing, construction facilities, and other industrial activities in Bangladesh [59]. In 1971 (after Independence), 
the cultivable land was 14.4 million hectares but this has since decreased to 8.44 million hectare [60]. This may be a result of the increased pressures of population growth, but is also heavily influenced by river bank erosion and landslides because of catastrophic weather events. Land use policy is also one of the most important issues enabling this decrease in cultivable land.

\section{Conclusions}

The majority (88\%) of farmer respondents indicated that they have experienced climate change effects over the two decades preceding the implementation of the study. Just a slight proportion fewer- 84 percent- of the farmers who responded in the study indicated that they had adopted coping strategies which help adapt their enterprises to environmental degradation like that expected under climate change, while the rest (16\%) did not adopt such practices. Various adaptation strategies were used by the farmers in response to altered farming resulting from experienced environmental degradation due to or similarly situated to events associated with climate change. Using an Adaptation Strategy Index, we ranked in the adaptation strategies in order by importance finding that irrigation was ranked as the first among farm adaptation strategies, while crop insurance has ranked as least important. Using these rankings as guidelines, policy makers and development practitioners can target actions in accordance with revised priorities. Further, continued studies by these agents using the methodological framework employed here can be used to continuously update priority areas for investment and policy creation to promote a policy, infrastructure and market environment which better enables further adoption of adaptive strategies.

The logistic regression model explained that out of eight selected factors, six of them (age, family size, farm size, education, family income and cooperative involvement) were statistically significant factors in relation to adoption of adaptive strategies. Therefore, we conclude that these six factors can be identified as influential characteristics of farmers who adopt coping strategies to climate change effects. Interestingly, three factors showed results of being not statistically significant: credit received, extension training, and market access. Should this results hold in additional studies with larger samples, the implications for policy makers and implementers of development assistance could be large; as central tenants of many development interventions, continued results of statistical insignificance may imply that, at least in terms of promotion "climate smart" adaptation strategy adoption by farmers, these mechanisms hold little importance and that a reorientation of development intervention priorities would be warranted. Further, although different supports and technological interventions may be available, lack of available water, shortage of cultivable land, and unpredicted weather appeared to be the major problems farmers encounter in adopting climate change adaptation strategies. Agricultural technologies (e.g., varieties resistant to salinity and droughts), credits and inputs such as seeds, fertilizers, pesticides, and irrigation should be made available locally to farmers. Policy mechanisms which support related infrastructure development, enable cost-effective access to agricultural inputs, and subsidize initial investments- either directly or through credit market interventions- are all areas on which policy makers should focus in the region, given the results reported here. Improvements in these factors may lead to increased production yields and greater incomes, further enabling additional adaptation to climate change effects in the future. 
This study represents a preliminary venture into understanding farmer behavior and perceptions related to adaptation for global climate change. It opens the door for continued, in-depth research on socio-economic influences which can inform policy makers- both in Bangladesh and across the globe- on how to tailor interventions across the spectrum so as to facilitate a shift in farming practices which achieves development goals under increasingly adverse climatic conditions. This continued research ought to focus not only on correlated influencers, as this study has done, but expand, when and where possible, into understanding the causation of adaptive behavior adoption. One promising and important area, made clear by comments by peers in publishing this work, is the need to determine the directionality and causation related to household income levels and adaptive strategy adoption. Continued research should also take the preliminary findings here as a guideline for targeting key factors which can be directly impacted by policy — such as extension service provision and credit and market access interventions - for further study which develops a more robust understanding of how these factors influence adaptive behaviors. Further, there is room, within a more robust study with greater resources at the team's disposal, to explore important interaction variables, such as land-tenure status, labor endowments of the household, competing resource allocation problems on the farm or in the household, and marginal status of farm families or farm lands.

\section{Acknowledgments}

The authors are grateful to the participant farmers from the study area, Momen, Sarker and Maruf for their kind assistance regarding data collection of this study. The paper is based on the first author's graduate study at Humboldt University of Berlin (HUB), Germany under Erasmus Mundus Scholarship funded by European Commission (EC).

\section{Author Contributions}

Mohammed Nasir Uddin is the primary author. He designed the field study, implemented data collection, and selected and implemented the analytical methodology. The work presented here is an extension of that completed for his master thesis, successfully defended for the International Master of Rural Development with its Secretariat at Universiteit Ghent, Belgium.

Wolfgang Bokelmann was the faculty advisor and thesis promoter of Mohammed Nasir Uddin. He contributed to the project inception, selection of the methodological framework, and writing of the thesis document upon which this article is based in an advisory capacity.

Jason S. Entsminger, as a native English speaker, was an editorial author, contributing writing and editing and responding to peer reviewers, in addition to substantive contributions on content in various sections including introductory and concluding remarks, and description and justification of the methodological framework.

\section{Conflicts of Interest}

The authors declare no conflict of interest. 


\section{References}

1. Intergovernmental Panel on Climate Change (IPCC). Climate Change 2007: Impacts, Adaptation and Vulnerability: An Assessment Report of the Intergovernmental Panel on Climate Change; Cambridge University Press: Cambridge, UK, 2007.

2. Intergovernmental Panel on Climate Change (IPCC). Climate Change 2001: Impacts, Adaptation, and Vulnerability; Contribution of Working Group II to the Third Assessment Report of the Intergovernmental Panel on Climate Change; Cambridge University Press: Cambridge, UK, 2001.

3. Intergovernmental Panel on Climate Change (IPCC). Climate Change 2013: The Physical Science Basis; Contribution of Working Group I to the Fifth Assessment Report of the Intergovernmental Panel on Climate Change; Cambridge University Press: Cambridge, UK, 2013.

4. Intergovernmental Panel on Climate Change (IPCC). Climate Change-2001; Special Report on the Regional Impacts of Climate Change: An Assessment of Vulnerability; Cambridge University Press: Cambridge, UK, 2001.

5. Rosegrant, M.W.; C. Ringler, T.; Benson, X.; Diao, D.; Resnick, J.; Thurlow, M.; Orden, D. Agriculture and Achieving the Millennium Development Goals; World Bank Report No. 32729-GLB; World Bank: Washington, DC, USA, 2008.

6. Swearingen, W.; Bencherifa, A. An Assessment of the drougth hazard in Morocco. In Drought: A Global Assessment; Wilhite, D.A., Ed.; Routledge: London, UK, 2000; Volume 1, pp. 279-286.

7. Mortimore, M.J.; Adams, W.M. Farmer adaptation, change and "crisis" in the Sahel. Glob. Environ. Chang. 2001, 11, 49-57.

8. Southworth, J.; Pfeifer, R.A.; Habeck, M.; Randolph, J.C.; Doering, O.C.; Rao, D.G. Sensitivity of winter wheat yields in the midwestern United States to future changes in climate, climate variability, and $\mathrm{CO}_{2}$ fertilization. Clim. Res. 2002, 22, 73-86.

9. Howden, S.M.; Soussana, J.; Tubiello, F.N.; Chhetri, N.; Dunlop, M.; Meinke, H. Adapting agriculture to climate change effects. Proc. Natl. Acad. Sci. USA 2007, 104, 19691-19696.

10. Rosegrant, M.W.; Cline, S.A. Global food security: Challenges and policies. Science 2003, 302, 1917-1919.

11. Eckhardt, N.A.; Cominelli, E.; Galbiati, M.; Tonelli, C. The future of science: Food and water for life. Plant Cell. 2009, 21, 368-372.

12. Asfaw, S.; Lipper, L. Economics of PGRFA Management for Adaptation to Climate Change: A Review of Selected Literature; Background Study Paper No. 60; Agricultural Economic Division: Rome, Italy, 2011.

13. Eakin, H. Institutional change, climate risk, and rural vulnerability: Cases from Central Mexico. World Dev. 2005, 33, 1923-1938.

14. Morton, J.F. The impact of climate change on smallholder and subsistence agriculture. Proc. Natl. Acad. Sci. USA 2007, 104, 19680-19685.

15. Ministry of Environment and Forest. Bangladesh Climate Change Strategy and Action Plan 2008; Government of the People's Republic of Bangladesh: Dhaka, Bangladesh, 2008.

16. GoB, Government of Bangladesh. Cyclone sidr in Bangladesh: Damage, Loss and Needs Assessment for Disaster recovery and Reconstruction. Available online: http:/gfdrr.org/docs/ Assessment Report_Cyclone\%20Sidr_Bangladesh_2008.pdf (accessed on 26 July 2013). 
17. Uddin, M.N. An Analysis of Farmers' Perception and Adaptation Strategies of Climate Change in Bangladesh. Master's Thesis, Humboldt University of Berlin, Berlin, Germany, 2012.

18. Asian Development Bank. Bangladesh: 2004 Flood, Response, Damage and Recovery; Asian Development Bank: Manila, Philippines, 2004.

19. Bangladesh Center for Advanced Studies. Cyclones' 91: A Follow up Study; Bangladesh Center for Advanced Studies: Dhaka, Bangladesh, 1991.

20. Deressa, T.D.; Hassan, R.M.; Ringler, C.; Alemu, T.; Yesuf, M. Determinants of farmers' choice of adaptation methods to climate change effects in the Nile Basin of Ethiopia. Glob. Environ. Chang. 2009, 19, 248-255.

21. Amha, R. Impact Assessment of Rainwater Harvesting Ponds: The Case of Alaba Woreda, Ethiopia. Master's Thesis, Addis Ababa University, Addis Ababa, Ethiopia, December 2006.

22. Ramasmasy, R.; Baas, S. Climate Variability and Change: Adaptation to Drought in Bangladesh. A Resource Book and Training Guide; Abu Dhabi Ports Company, Thailand and Food and Agriculture Organization of the United Nations: Rome, Italy, 2007.

23. Gujarati, D.N.; Porter, D.C. Basic Econometrics, 5th ed.; McGraw-Hill: New York, NY, USA, 2009.

24. Studenmund, A.H. Using Econometrics: A Practical Guide, 5th ed.; Pearson-Addison Wesley: New York, NY, USA, 2006

25. Rahm, M.R.; Huffman, W.E. The adoption of reduced tillage: The role of Human capital and other variables. Am. J. Agric. Econ. 1984, 72, 405-413.

26. Dhaka, B.L.; Chayal, K.; Poonia, M.K. Anaysis of farmers' perception and adaptation srategies to climate change. Libyan Agric. Res. Cent. J. Int. 2010, 1, 388-390.

27. Abedin, M.A.; Habiba, U.; Shaw, R. Health: Impacts of salinity, arsenic and drought in South-western Bangladesh. In Environment Disaster Linkages (Community, Environment and Disaster Risk Management); Shaw, R., Tran, P., Eds.; Emerald Group Publishing Limited: Bingley, UK, 2012; Volume 9, pp. 165-193.

28. Huq, S.; Ayers, J. Climate Change Impacts and Responses in Bangladesh. Available online: http://www.pedz.uni-mannheim.de/daten/edz-ma/ep/08/EST19195.pdf (accessed on 9 September 2013).

29. Rahman, M.M. Country report: Bangladesh. In Proceedings of the 2011 ADBI-APO Workshop on Climate Change and Its Impact on Agriculture, Seoul, Korea, 13-16 December 2011.

30. Paul, J.C.; Mishra, J.N.; Pradhan, P.L.; Panigrahi, B. Effect of drip and surface irrigation on yield, wateruse- efficiency and economics of capsicum (capsicum annum 1.) Grown under mulch and non mulch conditions in eastern coastal India. Eur. J. Sustain. Dev. 2013, 2, 99-108.

31. Tolga, E.; Yesim, E.; Halim, O.; Hakan, O. Water-yield relationships of potato under different irrigation methods and regimens. Sci. Agric. 2006, 63, 226-231.

32. El-Ashry, M.T.; Schilfgaarde, J.V.; Schiffman, S. Salinity pollution from irrigated agriculture. J. Soil Water Conserv. 1985, 40, 48-52.

33. Aza-Gnandji, C.D.R.; Xu, Y.; Raitt, L.; Levy, J. Salinity of irrigation water in the Philippi farming area of the Cape Flats, Cape Town, South Africa. Earth Sci. 2013, 39, 199-210.

34. Alam, M.R.; Ali, M.A.M.; Hossain, A.; Molla, M.S.H.; Islam, F. Integrated appraoch of pond based farming systems for sustainable production and income generation. Bangladesh J. Agric. Res. 2009, 34, 577-584. 
35. Mangala, B. Impact of Integratred Farming System on Socio-Economic Status of Bharatiya Agroindustries Foundation (BAIF) Beneficiary Farmer. Master's Thesis, University of Agricultural Sciences, Dharward, India, July 2008.

36. Uddin, M.T.; Takeya, H. Resource interdependence and enterprise combination of integrated farming in some selected areas of Bangladesh. Pak. J. Biol. Sci. 2005, 8, 405-412.

37. Ugwumba, C.O.A.; Okoh, R.N.; Ike, P.C.; Nnabuife, E.L.C.; Orji, E.C. Integrated farming system and its effect on farm cash income in Awka south agricultural zone of Anambra State, Nigeria. Am.-Eurasian J. Agric. Environ. Sci. 2010, 1, 1-6.

38. World Bank. Agricultural Insurance in Bangladesh: Promoting Access to Small and Marginal Farmers; Report No. 53081-BD; The World Bank: Washington, DC, USA, 2010.

39. Acquah, H.D. Farmers' perception and adaptation to climate change effects: A willingness to pay. J. Sustain. Dev. Afr. 2011, 13, 150-161.

40. Quayum, M.A.; Ali, A.M. Adoption and diffusion of power tiller in Bangladesh. Bangladesh J. Agric. Res. 2012, 37, 307-325.

41. Adeogun, O.A.; Ajana, A.M.; Ayinla, O.A.; Yarhere, M.T.; Adeogun, M.O. Application of logit model in adoption decision: A study of hybrid clarias in Lagos State, Nigeria. Am.-Eurasian J. Agric. Environ. Sci. 2008, 4, 468-472.

42. Bhuiyan, M.S.R. A Study on the Nature of Utilization of Power Tillers vis-à-vis Draft Power in Mymensingh and Jamalpur District. Master's Thesis, Bangladesh Agricultural University, Mymensigh, Bangladesh, November 1981.

43. Asaduzzaman, M. Impact of Agricultural Mechanization in Bangladesh; Research Report: 72; Bangladesh Institute of Development Studies (BIDS): Dhaka, Bangladesh, 1988.

44. Alam, S. Factors affecting adoption and use of power tillers in Bangladesh agriculture-An economic study. In Bureau of Socio-Economic Research and Training; Bangladesh Agricultural University: Mymensigh, Bangladesh, 1995; pp. 1-54.

45. Jaim, W.M.H.; Mizanur, R. Agricultural mechanization through private sector: A case of power tiller for multiple uses. In Proceedings of the 1999 Farm Economy Conference, Dhaka, Bangladesh, 15-16 July 1999.

46. Deressa, T.; Hassan, R.M.; Alemu, T.; Yesuf, M.; Ringler, C. Analyzing the Determinants of Farmers' Choice of Adaptation Methods and Perceptions of Climate Change in the Nile Basin of Ethiopia; IFPRI Discussion Paper 00798; International Food Policy Research Institute (IFPRI): Washington, DC, USA, 2008.

47. Mignouna, D.B.; Manyong, V.M.; Rusike, J.; Mutabazi, K.D.S.; Senkondo, E.M. Determinants of adopting imazapyr-resistant maize technologies and its impact on household income in Western Kenya. AgBioForum 2011, 14, 158-163.

48. Tiamiyu, S.A.; Akintola, J.O.; Rahji, M.A.Y. Technology adoption and productivity difference among growers of new rice for Africa in Savanna Zone of Nigeria. Tropicultura 2009, 27, 193-197.

49. Neil, S.P.; Lee, D.R. Explaining the Adoption and Disadoption of Sustainable Agriculture: The Case of Cover Crops in Northern Honduras; Cornell University Working Paper 1999-31; Cornell University: Ithaca, NJ, USA, December 1999.

50. Shively, G.E. Poverty, consumption risk, and soil conservation. J. Dev. Econ. 2001, 65, 267-290. 
51. Shiferaw, B.; Holden, S.T. Resource degradation and adoption of land conserving technologies in the Ethiopian highlands: A case study in Andit Tid, North Shewa. J. Int. Assoc. Agric. Econ. 1998, 18, doi:10.1016/S0169-5150(98)00036-X.

52. Polson, R.A.; Spencer, D.S.C. The technology adoption process in subsistence agriculture: The case of Cassava in Southwestern Nigeria. Agric. Syst. 1991, 36, 65-78.

53. Moser, C.M.; Barrett, C.B. The disappointing adoption dynamics of a yield-increasing, low external-input technology: The case of SRI in Madagascar. Agric. Syst. 2003, 76, 1085-1100.

54. Kim, C.; Jung, H.; Lee, S.; Park, S.; Takei, A. An analysis on determinants of farmers' adaptation to climate change in Korea. J. Rural Dev. 2012, 35, 53-72.

55. Gbetibouo, G.A. Understanding Farmers' Perceptions and Adaptations to Climate Change and Variability: The Case of the Limpopo Basin, South Africa; IFPRI Discussion Paper; International Food Policy Research Institute (IFPRI): Washington, DC, USA, 2009. Available online: http://Www.Ifpri.Org/Sites/Default/Files/Publications/Ifpridp00849.Pdf (accessed on 13 July 2012).

56. Nhemachena, C.; Hassan, R.H. Micro-Level Analysis of Farmers' Adaptation to Climate Change in Southern Africa; IFPRI Discussion Paper No. 00714; International Food Policy Research Institute: Washington, DC, USA, 2007. Available online: http://ageconsearch.umn. edu/handle/42399 (accessed on 26 July 2013)

57. Hossain, K.Z.; Rayhan, S.J.; Arif, M.N.; Rahman, M.M. Farmers' problem confrontation towards seed potato production. Dev. Ctry. Stud. 2011, 1, 27-33.

58. Alam, M.O.; Rashid, M.U. Problem confrontation of costal youth in undertaking selected agricultural activities in two village under Bhola District. Bangladesh Res. Publ. J. 2010, 4, 165-171.

59. Muhammed, N.; Koike, M.; Sajjaduzzaman, M. Land tenure complexities of sal in Bangladesh. Int. J. Agric. Biol. 2005, 7, 318-320

60. Bangladesh Bureau of Statistics. Ministry of Planning; Government People's Republic of Bangladesh: Dhaka, Bangladesh, 2006.

(C) 2014 by the authors; licensee MDPI, Basel, Switzerland. This article is an open access article distributed under the terms and conditions of the Creative Commons Attribution license (http://creativecommons.org/licenses/by/4.0/) 